\title{
Assemblage level variation in springtail lower lethal temperature: the role of invasive species on sub-Antarctic Marion Island
}

\author{
C H A R LENE JANION ${ }^{1}, M$. ROGER W ORLAND ${ }^{2}$ and \\ S T EVEN L. C H OW N ${ }^{1}$ \\ ${ }^{1}$ Centre for Invasion Biology, Department of Botany and Zoology, Stellenbosch University, South Africa and ${ }^{2}$ British Antarctic \\ Survey, NERC, Cambridge, U.K.
}

\begin{abstract}
It is widely held both in the physiological literature, and more generally, that the average characteristics of species within an assemblage differ among sites. Such generalizations should be based on investigations of whole assemblages at sites, but this is rarely done. Here, such a study is undertaken for virtually the full assemblage of springtails found at sub-Antarctic Marion Island, by investigating supercooling points (SCPs) of 12 of the 16 species that occur there. Assemblage level variation tends to be less than that documented for assemblages across northern hemisphere sites but similar to that found at some Antarctic locations. Across this set of species, the mean SCPs of the indigenous species (mean $\pm \mathrm{SE}=-17.2 \pm 0.4^{\circ} \mathrm{C}$ ) do not differ significantly from that of the invasive species $\left(-16.3 \pm 0.7^{\circ} \mathrm{C}\right)$. Overall, the introduction of several species to the island does not appear to have led to functional homogenization (for this trait). By combining the assemblage-level SCP data with information on the abundances of the species in each of four major habitats, it is also shown that severe but uncommon low temperature events could substantially alter species relative abundances. By resetting assemblage trajectories, such events could play an important role in the terrestrial system at the island.
\end{abstract}

Key words. Biological invasion, cold hardiness, functional homogenization, macrophysiology, relative abundance.

\section{Introduction}

It has long been thought that, in extra-tropical environments, physical factors are of prime importantance for limiting the abundance and richness of species. This idea, which stretches back to Darwin, as well as explorations by Schmalhausen (1949) and Fischer (1960), is now established in concepts such as adversity selection (Southwood, 1988). More recently, the tropical (niche) conservatism hypothesis has promoted the idea that tropical organisms typically do not disperse into temperate regions because they cannot tolerate, and rarely evolve, resistance to adverse physical conditions, and especially low temperature (Wiens \& Graham, 2005).

\footnotetext{
Correspondence: Charlene Janion, Centre for Invasion Biology, Department of Botany and Zoology, Stellenbosch University, Private Bag X1, Matieland 7602, South Africa. Tel.: +2721 808 3396; fax: +2721 808 2995; e-mail: cjanion@sun.ac.za
}

In other words, physiological tolerances vary systematically through space in a consistent, reasonably predictable fashion.

At least for lower temperature thresholds, much work appears to support this notion (Prosser, 1986; Spicer \& Gaston, 1999; Sinclair et al., 2003a). Most of the data on which this generality is based originate from studies at the interspecific level. That is, a comparison is made of a group of species for which each species has a physiological trait measure (although, more recently, some ecologists now consider that a range-based climate envelope $=$ physiological tolerance; Bonier et al., 2007) and some measure of geographic position (Gaston et al., 2008). Similar work is also often undertaken at the intraspecific level (Spicer \& Gaston, 1999). However, the idea that physiological tolerances of a group of organisms generally vary between locations or major areas is one that should be tested at the assemblage level because this is the level at which any generality concerning differences in tolerances among areas is being made 
(Gaston et al., 2008). In other words, if it is argued that tropical species are typically less cold hardy than temperate ones, then the formal argument is that the average value of the character traits (i.e. averaged across all species in each assemblage) that are used to establish cold hardiness [such as supercooling point (SCP) and/or lower lethal temperature] differ significantly among the two sites (or more correctly the two assemblages, each of which can also be characterized by a single geographic location or a general statement about geographic position, such as a given latitudinal or altitudinal band). The rationale can be applied more generally to statements about the average characteristics (e.g. upper thermal limits, desiccation resistance, standard metabolic rate) of any two or more assemblages over a cline of any size (e.g. altitudinal, latitudinal or depth clines).

Studies of the variation in average characteristics of assemblages among sites are nonetheless uncommon. Those that have been conducted are usually associated with investigations of functional traits in plant assemblages and their responses to particular kinds of environmental settings (Fonseca et al., 2000) or in studies of morphology in animals as a proxy for function in an ecological setting (Gilbert, 1985; Price et al., 2000). Rarely are they undertaken for traits that would be recognized as explicitly physiological, such as lower lethal temperatures, metabolic rates, ultraviolet tolerance or desiccation resistance (although see Leinaas, 1981, 2002; Block, 1982; Sinclair et al., 2006) and then often species means are reported, rather than the mean and variance for the assemblage. In the few cases where assemblage level data are available, it is clear that variation in the trait of interest at a particular site or across a range of sites can be much more substantial than might be expected on the basis of generalizations about spatial variation in the mean value of a trait. For example, in one of the few studies reporting assemblage level data, Addo-Bediako et al. (2000) show that not only does the mean SCP in insects decline with latitude, but also variance in SCP increases. This is ascribed to an increase in the range of behavioural and physiological strategies adopted by insects to survive low temperatures as conditions become more severe. Nonetheless, the generality of this phenomenon remains unclear.

One way to remedy this situation is to increase the frequency with which assemblage-level investigations are undertaken, despite the obvious difficulty that, in most assemblages, many species are rare (Gaston, 1994; McNab, 2003). Notwithstanding the challenges associated with undertaking them, such studies are essential for understanding how variation in physiological traits is partitioned through space as well as the ecological implications of this. Not only would they provide more robust tests of ideas such as the tropical conservatism hypothesis, but also they could provide further insight into the ways in which assemblages are altered by current anthropogenic change (Chown et al., 2004; Chown \& Gaston, 2008). For example, among the many environmental changes associated with the introduction of non-indigenous species, homogenization (or differentiation) of assemblages is of substantial concern (McKinney \& Lockwood, 1999; McKinney, 2008). Although most work in this field deals with taxonomic homogenization/differentiation, it is suggested that changes in functional similarity may also be of considerable significance (Olden, 2006). For example, these changes might alter the way in which an entire assemblage responds to other perturbations, such as those associated with climate change or pollution (Stachowicz et al., 2002; Piola \& Johnston, 2006; Chown et al., 2007). However, this would depend to a large extent on the way in which the addition of non-indigenous species affects the mean and variance of the traits of interest at the assemblage level.

In the present study, an assemblage-level investigation of lower lethal temperature is provided in springtails from subAntarctic Marion Island aiming not only to establish ways in which this might be done, but also to investigate the extent to which invasive alien species may alter this characteristic of the assemblage. Although mean annual temperatures at the island are increasing (le Roux \& McGeoch, 2008), this warming is being accompanied by an increase in clear skies and the severity and frequency of freezing events (Chown \& Froneman, 2008). In consequence, this physiological trait is ecologically relevant.

\section{Materials and methods}

\section{Study site and animals}

Sub-Antarctic Marion Island (46 $\left.54^{\prime} \mathrm{S}, 37^{\circ} 45^{\prime} \mathrm{E}\right)$ has a cool, wet and windy climate that varies considerably with the island's elevation (1230 m a.s.l.) and has been showing substantial change over the last 50 years (Chown \& Froneman, 2008). Sixteen species of springtail have been recorded from the island, of which five are introduced (Deharveng, 1981; Gabriel et al., 2001).

Individuals of 12 of the 16 sixteen species of springtails (Table 1) were collected during April 2008, during the day and usually on relatively dry days after previous rain. Some

Table 1. Mean $\pm \mathrm{SE}\left({ }^{\circ} \mathrm{C}\right)$ supercooling points of the 12 springtail species investigated in the present study.

\begin{tabular}{lll}
\hline Species & $n$ & Mean \pm SE \\
\hline Indigenous & & \\
$\quad$ Isotoma marionensis & 20 & $-14.4 \pm 1.3$ \\
$\quad$ Sminthurinus granulosis & 16 & $-18.5 \pm 1.7$ \\
$\quad$ Cryptopygus antarcticus travei & 35 & $-16.3 \pm 1.3$ \\
$\quad$ Cryptopygus tricuspis & 33 & $-17.1 \pm 0.9$ \\
$\quad$ Tullbergia bisetosa & 46 & $-17.8 \pm 0.7$ \\
$\quad$ Sminthurinus tuberculatus & 20 & $-13.5 \pm 1.1$ \\
$\quad$ Cryptopygus dubius & 28 & $-21.0 \pm 0.9$ \\
Invasive & & \\
$\quad$ Megalothorax sp. & 14 & $-18.5 \pm 1.5$ \\
$\quad$ Ceratophysella denticulata & 19 & $-21.2 \pm 0.8$ \\
Isotomurus cf. palustris & 20 & $-12.9 \pm 1.4$ \\
$\quad$ Pogonognathellus flavescens & 25 & $-11.6 \pm 0.8$ \\
Parisotoma notabilis & 18 & $-19.1 \pm 1.4$ \\
\hline
\end{tabular}


species were collected in the field using an aspirator, whereas, for others, plant material known to contain particular springtail species was returned to the laboratory where the springtails were extracted using a sieve over a tray. Some species were more difficult to find than others: Frisea tilbrooki and Katianna marionensis are rare on Marion Island (Gabriel et al., 2001). Cryptopygus caecus was also difficult to collect and Hypogastrura viatica has not been seen subsequent to an initial report by Deharveng (1981). Specimens collected in the field were placed into $30-\mathrm{mL}$ plastic vials with moist Plaster-of-Paris substrates and small amounts of detritus as a food source and for shelter. They were returned to the laboratory within $3 \mathrm{~h}$ of collection. Both laboratory- and field-collected specimens were sorted to species level and kept in small plastic containers (diameter $4 \mathrm{~cm}$ ) with a base of moist Plaster-of-Paris mixed with charcoal, at $5^{\circ} \mathrm{C}(\mathrm{LD} 12: 12 \mathrm{~h})$ in temperaturecontrolled incubators (LABCON, South Africa; accurate to $\pm 1^{\circ} \mathrm{C}$ ) for $24 \mathrm{~h}$. Because the aim of the study was to examine variation in lower lethal-temperature in field-collected animals, multiple acclimation treatments were not adopted (for such work on several of these species, see Slabber et al., 2007).

\section{SCP determinations}

Cold hardiness was measured as the SCP (or crystallization temperature; Chown \& Nicolson, 2004) of the individuals of each species. Although it is well known that lower lethal temperatures may either lie above or below the SCP (Bale, 1987; Sinclair et al., 2003b), investigation of several of the species studied here, namely Pogonognathellus flavescens, Isotomurus cf. palustris, Ceratophysella denticulata, Cryptopygus antarcticus travei and Tullbergia bisetosa has shown that the lower lethal temperature established over a period of several hours (i.e. a brief exposure, rather than one of weeks or months) and SCP are equivalent (Slabber et al., 2007) as is the case for many other species (Sømme, 1982; Cannon \& Block, 1988; Sinclair \& Sjursen, 2001; Sinclair et al., 2003a). It has also been shown that SCP varies with season, moult, acclimation treatment and diurnal temperature fluctuations (Cannon \& Block, 1988; Worland \& Convey, 2001; Sinclair et al., 2003c; Worland et al., 2006; Slabber et al., 2007). In the present study, work was conducted within a single season (i.e. the onset of the sub-Antarctic winter, acknowledging that seasonal variation in climate on Marion island is small; le Roux, 2008) using a single holding protocol to retain differences related to field conditions and considering moult to be a natural source of variation that might influence the survival likelihood of individuals within an assemblage. Consequently, detailed influence of this variation was not explored. Rather, the characterization of assemblage-level properties at the onset of winter was investigated.

SCP were determined using a Mettler-Toledo Differential Scanning Calorimeter (DSC) 820 (Mettler-Toledo Ltd, U.K.) incorporating a mechanical intra-cooler (Lab-Plant Ltd, U.K.) capable of cooling to $-60^{\circ} \mathrm{C}$. The system was calibrated with indium (melting point $156.6{ }^{\circ} \mathrm{C}$, enthalpy $28.71 \mathrm{~J} \mathrm{~g}^{-1}$ ) and gallium (melting point $29.81^{\circ} \mathrm{C}$, enthalpy of $79.3 \mathrm{~J} \mathrm{~g}^{-1}$ ).
Calibration was regularly checked by measuring the melting point of $0.5 \mu \mathrm{L}$ drops of high-performance liquid chomatography grade water. Data generated by the DSC were analysed using the STARe software package (Mettler-Toledo Ltd). Six to 20 animals were placed in a sealed aluminium pan $(40 \mu \mathrm{L})$ and cooled at a rate of $1{ }^{\circ} \mathrm{C} \mathrm{min}^{-1}$ from +5 to $-30{ }^{\circ} \mathrm{C}$. Previous investigation of five of the species under study (see above) showed that a change in cooling rate did not affect the SCP (Slabber et al., 2007) and this is true also for other springtail species (Cannon, 1983; Worland, 2005). The SCP was taken as the lowest point reached before the exotherm produced by the latent heat of freezing of the animal's body fluid (Worland, 2005).

\section{Statistical analysis}

Assemblage level analyses can potentially be undertaken in two ways. Most commonly, trait mean values for each species are obtained and the assemblage then characterized using standard measures of central tendency and variance (AddoBediako et al., 2000; Gaston et al., 2008; Greve et al., 2008). For comparison of the present results with those obtained in other studies, this approach was also adopted here. Differences between the SCP means of the indigenous and invasive species were also investigated, to determine the extent to which the results obtained by Slabber et al. (2007) generalize, using a generalized linear model assuming a Poisson distribution and an identity link function as implemented in Statistica version 8 (StatSoft, Tulsa, Oklahoma) (Sinclair et al., 2006). Differences between SCPs for different species were also assessed assuming a Poisson distribution and using an identity link function as implemented in Statistica, version 8 .

A second analysis was undertaken to determine the extent of individual-level variation within the assemblage because SCP values vary considerably within a given species at a given time (Cannon \& Block, 1988; Sinclair et al., 2003a). The aim was to determine the extent to which the characteristics of the assemblage at this level are altered by the presence of invasive species (i.e. how much is functional diversity in this trait altered) and to determine whether particular low-temperature events are likely to alter the relative abundances of springtail species in the field. The outcomes of low temperature events play out at the level of the population rather than the species (Bale, 1987; Sinclair, 2001). Therefore, understanding how assemblages might be altered via interactions between different environmental change drivers must be explored at this level (Brook et al., 2008).

For this approach, frequency distributions of the SCPs across the entire assemblage were constructed using the approaches recommended by Scott (1979). This procedure was repeated separately for the indigenous and non-indigenous assemblages, using the class number and limits of the full analysis. In each case, the mean, variance, maxima and minima, skewness and kurtosis were calculated, and the latter was tested for significance using $t$-statistics (Quinn \& Keough, 2002). The frequency distributions of the SCP values for the 
indigenous and invasive species were also compared using a Kolmogorov-Smirnov two-sample test.

The likely change in the abundance (and relative abundance) of indigenous and invasive species was also investigated. First, the proportion of the sample of individuals surviving a particular temperature was calculated for each species. These values were then multiplied by the species abundances in four major habitats investigated by Gabriel et al. (2001), namely Poa cookii tussock grassland, Azorella selago cushion plants, Jamesoniella-dominated mires and high-altitude mires. The difference between the original and low temperatureaffected assemblages was then inspected visually using rankabundance plots (Magurran, 2004). The temperatures selected for the comparisons were based on a long-term soil temperature record (2002-2007) for nine sites (0-800 m a.s.1.) at Marion Island (Slabber et al., 2007) and, specifically, these were $-6{ }^{\circ} \mathrm{C}$ and $-12{ }^{\circ} \mathrm{C}$. As an extreme temperature, we included $-16{ }^{\circ} \mathrm{C}$ because it lies close to the mean of the assemblage-level frequency distributions. Owing to the difficulty of finding C. caecus, SCP data for Cryptopygus tricuspis were used for this species, acknowledging the potential for differences between the species, although they are closely related (Stevens et al., 2006).

\section{Results}

Mean \pm SE SCP of the assemblage was $-16.9 \pm 3.14{ }^{\circ} \mathrm{C}$ and varied between $-21.3{ }^{\circ} \mathrm{C}$ in $C$. denticulata and $-11.6{ }^{\circ} \mathrm{C}$ in $P$. flavescens (Table 1). Significant differences in SCPs were found among species $\left(\chi^{2}=70.59, P=0.001\right)$. The indigenous species showed a slightly narrower range in SCP $(-13.6$ to $-21.0{ }^{\circ} \mathrm{C}$ ), but no difference was found between the groups using the species means $\left(\chi^{2}=0.012, P=0.913\right)$. This lack of difference was maintained when the species values were examined including only data below $-12{ }^{\circ} \mathrm{C}\left(\chi^{2}=0.082\right.$, $P=0.7703)$.

At the individual level, a much larger range in SCP values was found (Fig. 1). The distributions did not appear to differ between the indigenous and introduced species, and this was borne out by the two-sample Kolmogorov-Smirnov test $(P>0.10)$. Unsurprisingly, the statistical descriptions of the two distributions did not differ to any large extent (Table 2) and neither of the distributions showed significant skewness, although both were significantly platykurtic, perhaps unsurprising given their bimodal distributions. Although distributions are frequently divided into high and low group individuals and analysed further (Block, 1982; Sømme \& Block, 1982; Sinclair et al., 2006), this was not performed in the present study because preliminary analyses indicated that no further differences among the two groups of species would be found and because changes in the relative proportions of individuals in the groups were not the subject of investigation (for such an approach, see Klok \& Chown, 1998; Sinclair et al., 2006).

Assuming that the relative proportions of individuals surviving $-6{ }^{\circ} \mathrm{C}$ and $-12{ }^{\circ} \mathrm{C}$ in the laboratory would be reflected in the field, it is clear that the higher temperature has relatively little impact on the relative abundances of the
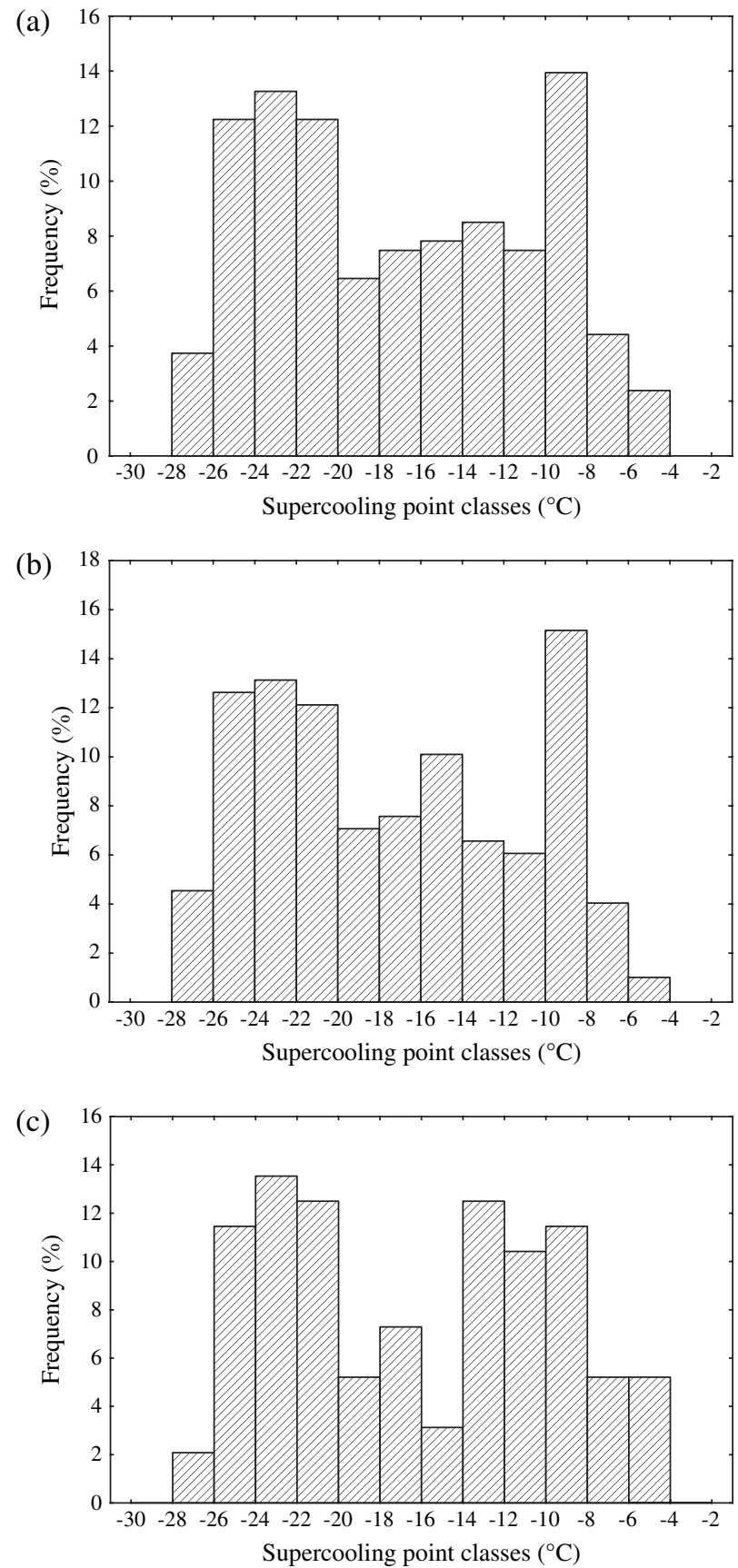

Fig. 1. Frequency distributions of the supercooling points for: (a) all springtail species investigated, (b) indigenous species only and (c) invasive species only.

species concerned within each of the four habitat types investigated (Fig. 2). By contrast, $-12{ }^{\circ} \mathrm{C}$ has a much more marked influence, changing the relative rankings of several of the species concerned. These included changes in rank among the indigenous and invasive species. For example, in the $P$. cookii tussock grassland, the indigenous Sminthurinus tuberculatus and invasive Parisotoma notabilis switched relative rankings, with substantial changes in abundance of the former by 
Table 2. Summary statistics for the frequency distributions of supercooling points for the springtail assemblages on Marion Island, including data from all the species investigated, the indigenous species only and the invasive species only.

\begin{tabular}{lccc}
\hline & All species & Indigenous & Invasive \\
\hline$n$ & 294 & 198 & 96 \\
Mean & -16.9 & -17.2 & -16.3 \\
Median & -17.4 & -17.9 & -16.5 \\
SE & 0.367 & 0.441 & 0.657 \\
Min & -27.3 & -27.3 & -26.7 \\
Max & -4.8 & -5.5 & -4.8 \\
Range & 22.5 & 21.8 & 21.9 \\
Skewness & 0.179083 & 0.212610 & 0.101534 \\
SE Skewness & 0.142135 & 0.172778 & 0.246210 \\
Kurtosis & $-1.30773 *$ & $-1.28178^{*}$ & $-1.36935^{*}$ \\
SE Kurtosis & 0.28332 & 0.343885 & 0.487732 \\
\hline
\end{tabular}

*Significance of kurtosis $(P<0.05)$ as determined using a $t$-test.

comparison with the latter species (Fig. 2a). Inspection of the frequency distributions suggested that splitting the distributions at $-16^{\circ} \mathrm{C}$ would reasonably differentiate between high and low group individuals (Block, 1982; Sinclair et al., 2003c). Using this temperature as a cut-off for population survival in a similar way results in much more dramatic changes to the relative abundance rankings of the species in each of the habitats investigated (Fig. 2).

\section{Discussion}

The assemblage approach adopted in the present study is unusual by the standards of most modern, comparative work. However, as pointed out by Gaston et al. (2008), this is the only approach that can justifiably support a conclusion that assemblages differ on average in some characteristic among areas. Moreover, it is also the only approach that can enable generalizations to be developed of the different ways in which major groups of organisms might deal with similar environmental stresses (Bartholomew, 1987; Rubinstein, 1992; Huey et al., 2002), a theme of considerable importance given current environmental change. Although it might be tempting to argue that the responses of each species are so contingent on conditions that generalization is precluded, this is frequently not the case, with generalizations often emerging at broader spatial and temporal scales (Lawton, 1999; Chown et al., 2003; Hodkinson, 2003).

In this particular instance, the range of mean $\mathrm{SCP}$ values recorded for the species is similar to the lower lethal temperature variation recorded by Addo-Bediako et al. (2000) for a latitudinal band encompassing $40-60^{\circ} \mathrm{S}$ (Fig. 2a). By contrast, it is much narrower than for a similar area in the Northern hemisphere, although this may be a result of the larger number of species studied in the latter case. The range of values found in the present study is also similar to that that recorded by Sinclair et al. (2006) for a much colder, Antarctic continental site at Cape Hallett $\left(-14.6\right.$ to $\left.-25.8^{\circ} \mathrm{C}\right)$. However, the typical median values of the Cape Hallett species are lower than those found here. Moreover, Sinclair et al. (2006) note that their study was conducted in the austral summer and conclude that winter SCP values in the species that they examined are likely to be much lower. A similar range of SCP values to that found in the present study is also recorded for springtails at the maritime Antarctic Signy Island (Sømme \& Block, 1982) but, again, the average values are lower than those found here. The present data thus suggest that the generalization that springtails are more cold tolerant at higher latitudes appears to be supported at the assemblage level, although work on temperate and tropical assemblages is required to fully support this conclusion.

Based on an investigation of 12 of the 16 species found on Marion Island, no differences are found, using species means, between the indigenous and invasive species present on the island. This outcome is different from that of previous a study by Slabber et al. (2007) using a smaller subset of species. However, that study shows that differences among the groups are most pronounced at the lowest acclimation temperatures, and less extensive after higher temperature acclimations. Nonetheless, both the mean data and the data from the individual level, as presented here, suggest that the two groups of species do not differ systematically in their SCPs, at least under the conditions in the field at this time of year. Consequently, it is reasonable to conclude that, at least from the perspective of this trait, invasion by the introduced species, which are mostly European in origin (Gabriel et al., 2001) has not contributed to functional homogenization or differentiation (Olden, 2006). Strictly speaking, such a conclusion requires comparison with another site, and perhaps the most striking one to be made is with nearby Prince Edward Island (19 km distant), which is free of introduced springtail species with the exception of $C$. denticulata (Hugo et al., 2006). If little difference in SCP is assumed among populations on the two islands, then the introduction of the four additional nonnative species to Marion Island has made little difference to the assemblage frequency distribution for SCP. Of course, this does not mean that other functional traits might not have changed, and this would appear to be the case for upper thermal tolerance, direction of thermal plasticity in desiccation resistance, and possibly also egg development rates (Chown et al., 2007; Slabber et al., 2007; Janion, 2008).

Despite the overall similarity in frequency distributions among the two groups, it is clear that, after a severe low temperature event (e.g. -12 to $-16^{\circ} \mathrm{C}$ ) substantial differences in the relative abundances of the different springtail species would be found, with this also varying among habitats. Such events, although uncommon, are likely to be important in structuring assemblages via their differential effects on populations (Parmesan et al., 2000; Lee et al., 2009). Clearly, survival of such an event is not the only factor likely to influence subsequent community dynamics, given that growth rates of each species, resource availability and interactions are all important. However, if any form of assembly rules operate in these systems, then changes in abundance may reset the assemblage trajectory (Drake, 1990; Weiher \& Keddy, 1995).

An important question is how frequent low temperature events of the kind explored in the present study are likely to be on Marion Island. Microclimate data collected for the 
(a) Poa cookii-dominated grassland

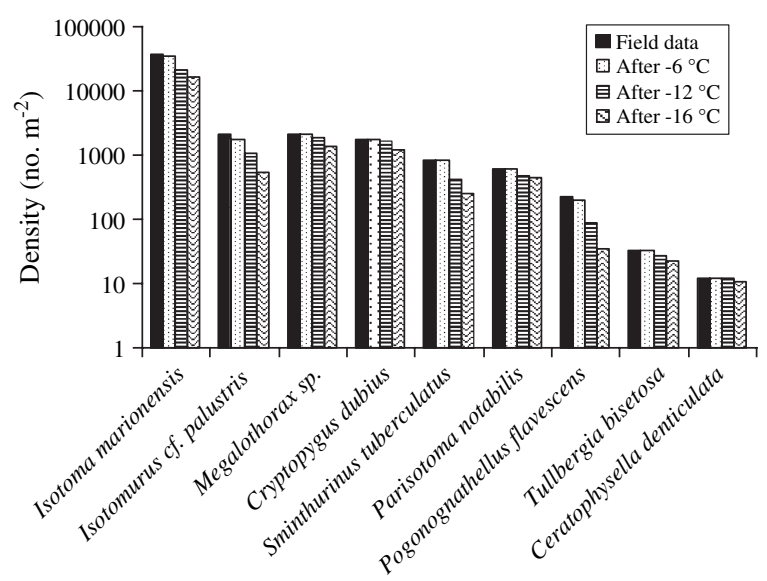

(b) Jamesoniella-dominated mires

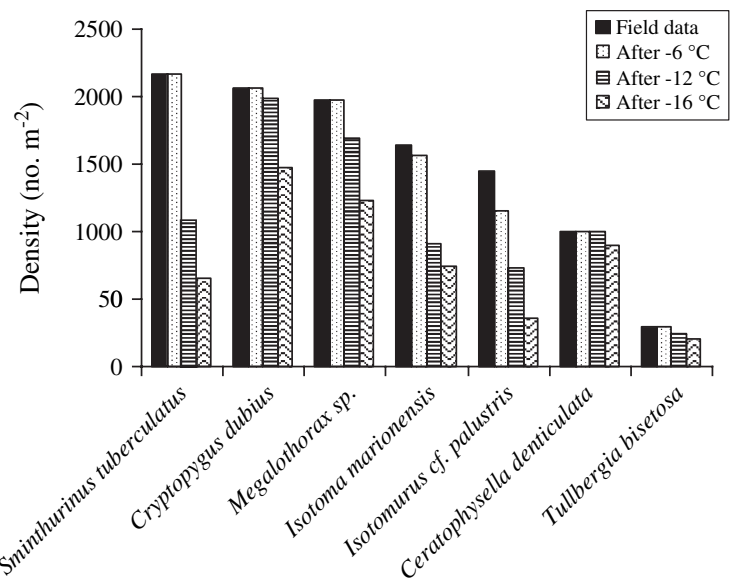

(c) High altitude mires

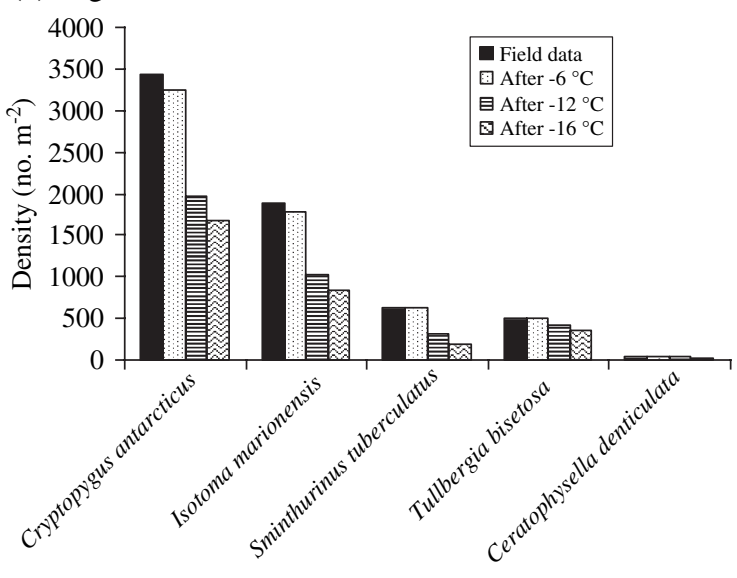

(d) Azorella selago cushion plants

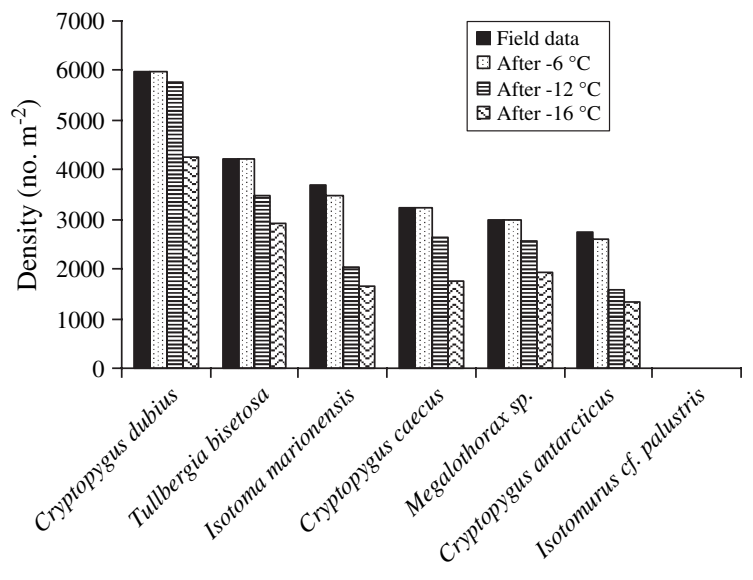

Fig. 2. Abundances (expressed as density, number of individuals per metre ${ }^{2}$ ) of springtail species in (a) Poa cookii-dominated grassland, (b) Jamesoniella-dominated mires, (c) high altitude mires and (d) Azorella selago cushion plants. In each case, the field data provided by Gabriel et al. (2001) are shown first, and then how low temperature events of increasing severity would affect abundances. In all cases, abundances decline, but the change in density of species relative to each other changes in several instances.

island in the range $0-800 \mathrm{~m}$ over several years suggest that, from $200 \mathrm{~m}$ upwards, events where temperatures decline to these levels (approximately $-13{ }^{\circ} \mathrm{C}$ ) are likely to be reasonably uncommon, occurring perhaps once every 3-5 years, with increasing frequency at higher elevations (Boelhouwers et al., 2003, Slabber et al., 2007; Lee et al., 2009). At sea level, such events seem entirely unlikely. Nonetheless, as noted above, uncommon, although extreme, events may have substantial effects on populations.

A further consideration is the extent to which populations may alter their lower lethal temperatures (or SCPs) in anticipation of extreme events. Acclimation ability (over a 1-week period) is known for three of the invasive (P. flavescens, Isotomurus $c f$. palustris and $C$. denticulata) and two of the indigenous species ( $C$. antarcticus and T. bisetosa) examined in the present study. Typically, acclimation ability in SCP is small and does not differ among the indigenous and invasive species, suggesting that such a response is not likely to be important, at least in these springtail species (Slabber et al., 2007). However, if such a population-level approach is to be adopted for understanding the likely effect of low temperature events on other springtail species or invertebrates, both shortand long-term variation in hardening and acclimation ability would have to be considered (Klok \& Chown, 1998; Worland \& Convey, 2001; Hoffmann et al., 2003; Sinclair et al., 2003c). For several species of terrestrial arthropods across a range of groups on Marion Island, the acclimation ability in SCPs is not well developed (Deere et al., 2006; Slabber et al., 2007; Marais et al., 2009), which may be a consequence of the unpredictability of changing conditions on the island (Deere \& Chown, 2006). However, in other species, this is not the case (Klok \& Chown, 1998; Slabber \& Chown, 2004, 2005).

In conclusion, the present study shows that an assemblagelevel investigation of a physiological trait is a useful way to explore the ecological consequences of trait variation, particularly for ecological characteristics that are an emergent property 
of assemblages (such as species rank abundance distributions). Moreover, the approach can provide an additional route for understanding the environmental context of physiological traits, and such an approach is growing in importance, as emphasized most notably by Baust \& Rojas (1985) and by Bale (1987).

\section{Acknowledgements}

We thank Melodie McGeoch for helpful discussion and John Terblanche and two anonymous referees for their helpful comments on a previous version of the manuscript. Logistic support in the field was provided by the South African National Antarctic Programme and funding for this work was provided partly by SA-Norway Grant 180349 to S.L. Chown/ H.P. Leinaas and by the British Antarctic Survey.

\section{References}

Addo-Bediako, A., Chown, S.L. \& Gaston, K.J. (2000) Thermal tolerance, climatic variability and latitude. Proceedings of the Royal Society of London B, 267, 739-745.

Bale, J.S. (1987) Insect cold hardiness: freezing and supercooling an ecophysiological perspective. Journal of Insect Physiology, 33, 899-908.

Bartholomew, G.A. (1987) Interspecific comparison as a tool for ecological physiologists. New Directions in Ecological Physiology (ed. by M. E. Feder, A. F. Bennett, W. W. Burggren and R. B. Huey), pp. 11-37, Cambridge University Press, U.K.

Baust, J.G. \& Rojas, R.R. (1985) Insect cold hardiness: facts and fancy. Journal of Insect Physiology, 31, 755-759.

Block, W. (1982) Supercooling points of insects and mites on the Antarctic Peninsula. Ecological Entomology, 7, 1-8.

Boelhouwers, J., Holness, S. \& Sumner, P. (2003) The maritime Subantarctic: a distinct periglacial environment. Geomorphology, 52, 39-55.

Bonier, F., Martin, P.R. \& Wingfield, J.C. (2007) Urban birds have broader environmental tolerance. Biology Letters, 3, 670-673.

Brook, B.W., Sodhi, N.S. \& Bradshaw, C.J.A. (2008) Synergies among extinction drivers under global change. Trends in Ecology and Evolution, 23, 453-460.

Cannon, R.J.C. (1983) Experimental studies on supercooling in two Antarctic micro-arthropods. Journal of Insect Physiology, 29, 617-624.

Cannon, R.J.C. \& Block, W. (1988) Cold tolerance of microarthropods. Biological Reviews, 63, 23-77.

Chown, S.L. \& Froneman, P.W. (2008) The Prince Edward Islands. Land-Sea Interactions in a Changing Climate. African SunMedia, South Africa.

Chown, S.L. \& Gaston, K.J. (2008) Macrophysiology for a changing world. Proceedings of the Royal Society of London B, 275, 14691478.

Chown, S.L. \& Nicolson, W.W. (2004) Insect Physiological Ecology. Mechanisms and Patterns. Oxford University Press, U.K.

Chown, S.L., Addo-Bediako, A. \& Gaston, K.J. (2003) Physiological diversity: listening to the large-scale signal. Functional Ecology, 17, 568-572.

Chown, S.L., Gaston, K.J. \& Robinson, D. (2004) Macrophysiology: large-scale patterns in physiological traits and their ecological implications. Functional Ecology, 18, 159-167.
Chown, S.L., Slabber, S., McGeoch, M.A. et al. (2007) Phenotypic plasticity mediates climate change responses among invasive and indigenous arthropods. Proceedings of the Royal Society of London $B, 274,2661-2667$.

Deere, J.A. \& Chown, S.L. (2006) Testing the beneficial acclimation hypothesis and its alternatives for locomotor performance. American Naturalist, 168, 630-644.

Deere, J.A., Sinclair, B.J., Marshall, D.J. \& Chown, S.L. (2006) Phenotypic plasticity of thermal tolerances in five oribatid mite species from sub-Antarctic Marion Island. Journal of Insect Physiology, 52, 693-700.

Deharveng, L. (1981) Collemboles des iles subantarctiques de l'Océan Indien Mission J. Travé 1972-1973. Comité National Française des Recherches Antarctiques, 48, 33-108.

Drake, J.A. (1990) Communities as assembled structures: do rules govern pattern? Trends in Ecology and Evolution, 5, 159-164.

Fischer, A.G. (1960) Latitudinal variations in organic diversity. Evolution, 14, 64-81.

Fonseca, C.R., Overton, J.J., Collins, B. \& Westoby, M. (2000) Shifts in trait-combinations along rainfall and phosphorus gradients. Journal of Ecology, 88, 964-977.

Gabriel, A.G.A., Chown, S.L., Barendse, J. et al. (2001) Biological invasions on Southern Ocean islands: the Collembola of Marion Island as a test of generalities. Ecography, 24, 421-430.

Gaston, K.J. (1994) Rarity. Chapman \& Hall, U.K.

Gaston, K.J., Chown, S.L. \& Evans, K.L. (2008) Ecogeographical rules: elements of a synthesis. Journal of Biogeography, $\mathbf{3 5}$, 483-500

Gilbert, F.S. (1985) Ecomorphological relationships in hoverflies (Diptera, Syrphidae). Proceedings of the Royal Society of London $B$, 224, 91-105.

Greve, M., Gaston, K.J., van Rensburg, B.J. \& Chown, S.L. (2008) Environmental factors, regional body size distributions and spatial variation in body size of local avian assemblages. Global Ecology and Biogeography, 17, 514-523.

Hodkinson, I.D. (2003) Metabolic cold adaptation in arthropods: a smaller-scale perspective. Functional Ecology, 17, 562-567.

Hoffmann, A.A., Sørensen, J.G. \& Loeschcke, V. (2003) Adaptation of Drosophila to temperature extremes: bringing together quantitative and molecular approaches. Journal of Thermal Biology, 28, 175-216.

Huey, R.B., Carlson, M., Crozier, L. et al. (2002) Plants versus animals: do they deal with stress in different ways? Integrative and Comparative Biology, 42, 415-423.

Hugo, E.A., Chown, S.L. \& McGeoch, M.A. (2006) The microarthropods of sub-Antarctic Prince Edward Island: a quantitative assessment. Polar Biology, 30, 109-119.

Janion, C. (2008) The effect of temperature on the egg development of Collembola from Marion Island: indigenous vs. invasive species. MSc Thesis, Stellenbosch University, South Africa.

Klok, C.J. \& Chown, S.L. (1998) Interactions between desiccation resistance, host-plant contact and the thermal biology of a leafdwelling sub-Antarctic caterpillar, Embryonopsis halticella (Lepidoptera: Yponomeutidae). Journal of Insect Physiology, 44, 615-628.

Lawton, J.H. (1999) Are there general laws in ecology? Oikos, 84, 177-192.

Lee, J.E., Janion, C., Marais, E. et al. (2009) Physiological tolerances account for range limits and abundance structure in an invasive slug. Proceedings of the Royal Society of London Series B, 276, $1459-1468$

Leinaas, H.P. (1981) Activity of Arthropoda in snow within a coniferous forest, with special reference to Collembola. Holarctic Ecology, 4, 127-138. 
Leinaas, H.P. (2002) UV tolerance, pigmentation and life forms in High Arctic Collembola. UV Radiation and Arctic Ecosystems (ed. by D.O. Hessen), pp. 123-133. Springer Verlag, Germany.

Magurran, A.E. (2004) Measuring Biological Diversity. Blackwell Publishing, U.K.

Marais, E., Terblanche, J.S. \& Chown, S.L. (2009) Life stagerelated differences in hardening and acclimation of thermal tolerance traits in the kelp fly Paractora dreuxi (Diptera, Helcomyzidae). Journal of Insect Physiology, 55, 336-343.

McKinney, M. (2008) Do humans homogenize or differentiate biotas? It depends. Journal of Biogeography, 35, 1960-1961.

McKinney, M.L. \& Lockwood, J. (1999) Biotic homogenization: a few winners replacing many losers in the next mass extinction. Trends in Ecology and Evolution, 14, 450-453.

McNab, B.K. (2003) Sample size and the estimation of physiological parameters in the field. Functional Ecology, 17, 82-86.

Olden, J.D. (2006) Biotic homogenization: a new research agenda for conservation biogeography. Journal of Biogeography, 33, 2027-2039.

Parmesan, C., Root, T.L. \& Willig, M.R. (2000) Impacts of extreme weather and climate on terrestrial biota. Bulletin of the American Meteorological Society, 81, 443-450.

Piola, R.F. \& Johnston, E.L. (2006) Differential resistance to extended copper exposure in four introduced bryozoans. Marine Ecology Progress Series, 311, 103-114.

Price, T., Lovette, I.J., Bermingham, E. et al. (2000) The imprint of history on communities of North American and Asian warblers. American Naturalist, 156, 354-367.

Prosser, C.L. (1986) Adaptational Biology. Molecules to Organisms. John Wiley and Sons, New York, New York.

Quinn, G.P. \& Keough, M.J. (2002) Experimental Design and Data Analysis for Biologists. Cambridge University Press, U.K.

le Roux, P.C. (2008) Climate and climate change. The Prince Edward Islands. Land-Sea Interactions in a Changing Ecosystem (ed. by S.L. Chown and P.W. Froneman), pp. 39-64. African SunMedia, South Africa.

le Roux, P.C. \& McGeoch, M.A. (2008) Changes in climate extremes, variability and signature on sub-Antarctic Marion Island. Climatic Change, 86, 309-329.

Rubinstein, B. (1992) Similarities between plants and animals for avoiding predation and disease. Physiological Zoology, 65, 473-492.

Schmalhausen, I.I. (1949) Factors of Evolution. The Theory of Stabilizing Selection. University of Chicago Press, Chicago, Illinois.

Scott, D.W. (1979) On optimal and data-based histograms. Biometrika, 66, 605-610.

Sinclair, B.J. (2001) Field ecology of freeze tolerance: interannual variation in cooling rates, freeze-thaw and thermal stress in the microhabitat of the alpine cockroach Celatoblatta quinquemaculata. Oikos, 93, 286-293.

Sinclair, B.J. \& Sjursen, H. (2001) Cold tolerance of the Antarctic springtail Gomphiocephalus hodgsoni (Collembola, Hypogastruridae). Antarctic Science, 13, 271-279.

Sinclair, B.J., Addo-Bediako, A. \& Chown, S.L. (2003a) Climatic variability and the evolution of insect freeze tolerance. Biological Reviews, 78, 181-195.
Sinclair, B.J., Vernon, P., Klok, C.J. \& Chown, S.L. (2003b) Insects at low temperatures: an ecological perspective. Trends in Ecology and Evolution, 18, 257-262.

Sinclair, B.J., Klok, C.J., Scott, M.B. et al. (2003c) Diurnal variation in supercooling points of three species of Collembola from Cape Hallett, Antarctica. Journal of Insect Physiology, 49, 1049-1061.

Sinclair, B.J., Terblanche, J.S., Scott, M.B. et al. (2006) Environmental physiology of three species of springtail at Cape Hallett, North Victoria Land, Antarctica. Journal of Insect Physiology, 52, 29-50.

Slabber, S. \& Chown, S.L. (2004) Thermal tolerance and cold hardiness strategy of the sub-Antarctic psocid Antarctopsocus jeanneli Badonnel. Polar Biology, 28, 56-61.

Slabber, S. \& Chown, S.L. (2005) Differential responses of thermal tolerance to acclimation in the sub-Antarctic rove beetle Halmaeusa atriceps. Physiological Entomology, 30, 195-204.

Slabber, S., Worland, M.R., Leinaas, H.P. \& Chown, S.L. (2007) Acclimation effects on thermal tolerances of springtails from subAntarctic Marion Island: indigenous and invasive species. Journal of Insect Physiology, 53, 113-125.

Sømme, L. (1982) Supercooling and winter survival in terrestrial arthropods. Comparative Biochemistry and Physiology A, 73, 519-543.

Sømme, L. \& Block, W. (1982) Cold hardiness of Collembola at Signy Island, maritime Antarctic. Oikos, 38, 168-176.

Southwood, T.R.E. (1988) Tactics, strategies and templets. Oikos, 52, 3-18.

Spicer, J.I. \& Gaston, K.J. (1999) Physiological Diversity and Its Ecological Implications. Blackwell Science, U.K.

Stachowicz, J.J., Terwin, J.R., Whitlatch, R.B. et al. (2002) Linking climate change and biological invasions: ocean warming facilitates nonindigenous species invasions. Proceedings of the National Academy of Sciences of the United States of America, 99, 15497-15500.

Stevens, M., Greenslade, P., Hogg, I.D. \& Sunnocks, P. (2006) Southern Hemisphere springtails: could any have survived glaciation of Antarctica? Molecular Biology and Evolution, 23, 574-882.

Weiher, E. \& Keddy, P.A. (1995) Assembly rules, null models, and trait dispersion: new questions from old patterns. Oikos, 74, 159-164.

Wiens, J.J. \& Graham, C.H. (2005) Niche conservatism: integrating evolution, ecology, and conservation biology. Annual Review of Ecology Evolution and Systematics, 36, 519-539.

Worland, M.R. (2005) Factors that influence freezing in the sub-Antarctic springtail Tullbergia antarctica. Journal of Insect Physiology, 51, 881-894.

Worland, M.R. \& Convey, P. (2001) Rapid cold hardening in Antarctic microarthropods. Functional Ecology, 15, 515-524.

Worland, M.R., Leinaas, H.P. \& Chown, S.L. (2006) Supercooling point frequency distributions in Collembola are affected by moulting. Functional Ecology, 20, 323-329.

Accepted 01 May 2009

First published online 15 June 2009 